\title{
SUSTAINING LIFE WITH TREES: ECOCRITICISM PERSPECTIVE IN SELECTED
} PICTURE BOOKS

\author{
Christy Tisnawijaya ${ }^{1 *} \&$ Geni Kurniati ${ }^{2}$ \\ ${ }^{1,2}$ Universitas Pamulang
}

Corresponding Author: Christy Tisnawijaya E-mail: christy.tisnawijaya@gmail.com

\begin{tabular}{l}
\hline ARTICLE INFO \\
\hline Received: 16-07-2021 \\
Accepted: $15-10-2021$ \\
Published: 30-10-2021 \\
Volume: 5 \\
Issue: 2 \\
DOI: \\
https://doi.org/10.33019/lire.v \\
5i2.121 \\
\hline KEYWORDS \\
\hline
\end{tabular}

Ecocriticism, picture books, sustaining life, trees \begin{abstract}
The issue of the environmental problem has been prevalent especially in the contemporary era. The fact that Mother Earth is currently facing a lot of environmental concerns is the central discussion of the selected children's picture books. Hence, this study aims to analyze how the picture books successfully capture the idea that trees are the symbol of Mother Earth per se. The selected picture books to be discussed are: A Tree is Nice by Janice May Udry (1984), The Giving Tree by Shel Silverstein (1992), Red Knit Cap Girl and The Reading Tree by Naoko Stoop (2014), Seasons Come, Seasons Go: Tree by Patricia Hegarty (2015) and The Tree by Neil Layton (2016). By scrutinizing the narrative and illustrative elements of the picture books, this study sheds light on how the ecosy stems are held together by trees. The trees play a vital role in ba lancing and maintaining the world's ecosystems. Moreover, the trees are valuable for providing en vironmental and social benefits. Hence, taking care of the trees can be perceived as maintaining a sustainable life for both the living a nd nonliving things. The underlying theories to support the discussion are those of ecocriticism, na rra tive and illustra tive elements, and the trees as metaphor of Mother Earth, all of which are interconnected in children's picture books.
\end{abstract}

\section{INTRODUCTION}

Through narrative and illustrative forms of environmental literacy, the discussion of Ecocriticism could be considered as a critical and creative tool for educating readers, particularly children, about environmental issues, while at the same time promoting sustainable practices for the future generation. Picture books have turned to the concept of valuable trees as a critical framework to bring human communities back to responsible and sustainable relationships with the environment. Understanding one's relationship to trees promotes greater ecological awareness because of the emotional and social relationship to Mother Earth. One way to achieve this is through tree-based stories. The attention to the trees continues to be the metaphor of Mother Earth in the selected picture books. They depict trees as the dominant subject and theme, underpinning other ecological concerns related to environmental issues. Moreover, these picture books pinpoint a range of

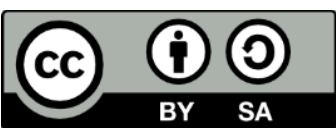

This work is licensed under Creative Commons Attribution-ShareAlike 4.0 Internasional. Copyright $@ 2021$, Christy Tisnawijaya, Geni Kurniati 
environmental tensions while they also subtly educate readers about the importance of trees in their lives. Environmental issues are the main concern of ecocriticism.

There are several articles posing the concern. First, Sigler (1994) in essay entitled Wonderland to Wasteland: toward Historicizing Environmental Activism in Children 's Literature uses the emerging methodologies of ecocriticism to describe and evaluate representations of what we now call "the environment" - that is, nonhuman nature - within the traditionally pastoral ethos of children's literature. Second, Dobrin (2004) in Wild Things: Children's Culture and Ecocriticism focuses on classic literary works such as Charlotte's Web and The Lorax as well as series fiction, nature magazines, environmental music and videos, the Muppets and other Jim Henson's productions, and Disney's latest theme park, Animal Kingdom. Third, Echterling (2016) in Postcolonial Ecocriticism, Classic Children's Literature, and the Imperial-Environmental Imagination in "The Chronicles of Narnia" explores a deep reverence for nonhuman nature and condemns its exploitation. Fourth, Beeck (2017) in Environmental Picture Books: Cultivating Conservationists asserts that scholars must pay greater attention to how texts represent and promote environmental awareness. Fifth, Goga (2018) in Children's Literature as an Exercise in Ecological Thinking emphasizes the importance of ecocritical perspectives on the relationship between literary characters and the environment, and discusses the need for an interspecies ethics. Moreover, Aslan and Bas (2020) review the relationship between man and nature in Ecocritical Approach to Children's Literature: Example of "I am a Hornbeam Branch". These articles show that from time to time, preserving nature is still a talking point in children's literature.

The ecocritics use the term 'nature' in a broader sense. Ecocriticism is not merely the study of nature as represented in literature. Nature here does not mean a mere fancy of its beautiful aspects like plants and animals. It means the whole of the physical environment consisting of the human and the nonhuman. The interconnection between the two creates a bond which is the basis of ecocriticism. As long as there is harmony between the living and the non-living, there prevails a healthy eco-system for the benevolence of mankind as well as the earth.

The modern ecological consciousness has a feeling that the balance between human and the natural world must be maintained. A perfect ecology is one in which plants, animals, birds, and human beings live in such harmony that none dominates or destroys the other. (Frederick, 2012, p. 147) 
Children need as much time and space as possible to be agents of their learning to draw on literature and on the other creative arts to access and express their feelings, and therefore to have enough contact with nature. The deep strain of ecological awareness in children's literature emerges in stories about the natural challenges in environmental narratives. These issues are relevant to the interests and concerns of ecocriticism. Some of the picture books portray such issues are: A Tree is Nice by Janice May Udry (1984), The Giving Tree by Shel Silverstein (1992), Red Knit Cap Girl and The Reading Tree by Naoko Stoop (2014), Seasons Come, Seasons Go: Tree by Patricia Hegarty (2015), and The Tree by Neil Layton (2016). The selected books have been discussed by others. Margarith (2014) in "The Giving Tree" at Fifty: Sadder Than I Remembered states that environmental activists rue the boy's pillaging of the tree and, by extension, the environment. Hulick (2014) in Review of the book Red Knit Cap Girl to the Rescue by Naoko Stoop deduces that Red Knit Cap Girl's adventures may inspire some fresh pretend play with stuffed animals. Oldham (2018) in Tree: A Peek-Through Picture Book by Patricia Hegartyillustrated by Britta Teckentrup exposes Follow Owl as the tree he inhabits changes with the seasons and how animals vary in those seasons. Stead (2019) in Be Gentle: What Is the Reason for Kindness? portrays that reading A Tree Is Nice by Janice May Udry is an ode to simple joy and claims that trees are very nice.

This study, entitled Sustaining Life with Trees: Ecocriticism Perspective in Selected Picture Books, therefore, at the challenge of expressing trees that provide sustaining life in children's literature. Abram (1996) opines that the written word may be partly responsible for estrangement in the relationship between humans and their environment. The scope of this study is literature with selected picture books as the objects of the study and is limited to ecocriticism perspective. The problem of this study, then, can be formulated as follows: 1) How do the narrative and illustrative elements of the selected picture books portray the trees? and 2) How are the trees exemplary of the Mother Earth that maintains a sustaining life in terms of environmental problems faced in the contemporary era?

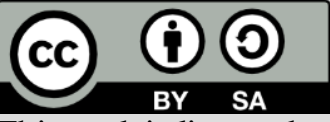




\section{LITERATURE REVIEW}

During the last few decades, the environment has posed a great threat to human society as well as Mother Earth. Ecocriticism arose as a new theory of reading nature writing. Ecocriticism is one of the revisionist movements, which has swept the humanities over the past few decades.

Eco and critic both derive from Greek, oikos and kritis and in tandem they me an "house judge," which may surprise many lovers of green, outdoor writing. A long-winded gloss on ecocritic might run as follows: "a person who judges the merits and faults of writings that depict the effects of culture upon nature, with a view toward celebrating nature's berating its despoilers, and reversing their harm through political action." So the oikos is nature, a place Edward Hoagland calls Jour widest home," and the kritos is an arbiter of taste who wants the house kept in good order, no boots or dishes strewn about to ruin the original décor. (Howarth, 1996, p. 69)

Moreover, Buell identifies two waves of ecocriticism, the first wave of ecocriticism focused on nature writing, nature poetry, and wilderness fiction (1995, p. 138). They were used to uphold the philosophy of organisms. Here the environment effectively means the natural environment. The wave aimed to preserve the 'biotic community'. The ecocritics of this wave apprised "the effects of culture upon nature, with a view toward celebrating nature, berating its despoilers, and reversing their harm through political action" (Howarth, 1996, p. 69). Thus, ecocriticism initially aimed at earth care. The second wave of ecocriticism inclined towards environmental justice issues and a 'social ecocriticism' that takes urban landscape as seriously as 'natural landscape' (Buell, 1995, p. 22). This wave of ecocriticism is also known as revisionist ecocriticism. It seeks to locate the vestiges of nature in cities and exposes crimes of eco-injustice against society's marginal section.

Ecocriticism advocates sustainable development for a better future for mankind in general. All organisms have their right to survive in their way. The plants, the animals, the women, the marginal, the tribal - all have their role to play to keep up the earth's basic life support system. Limited use of resources will ensure the safe and secure future of the generations to come. "The most common measure to tackle the environmental crisis is sustainable development". This categorically means the required use of natural resources without endangering the whole environment and the well-being of all human beings. Ecocriticism underlines environmental justice as man's voracious urge to conquer nature is somewhat misleading. We used to believe ourselves to be superior to the other life forms that inhabit the biosphere. However, now we realize 
that nature is not a subordinate but a co-inhabitant of this earth's ecosystem. We should change our self-destructive motives. If humans try to destroy nature, they will be paid back by their coins. Our global crisis is not because of how ecosystems function. It is because of how our ethical systems function. Getting through the crisis requires understanding our impact on nature. It requires understanding those ethical systems and using that understanding to reform them (Frederick, 2012, p. 128).

Ecocriticism is an intentionally broad approach that is by its very nature interdisciplinary. It draws its sustenance from the existing literary theories. All sciences come forward to contribute to the field. Therefore, new theories like Postcolonial Ecocriticism, Ecofeminism, Ecomarxism, Ecospiritualism are coming to light. However, they differ from the other theories in that while all of them consider earth as a social sphere, Ecocriticism considers it as an ecosphere. All other theories are marked by their ego-consciousness while Ecocriticism is characterized by Eco consciousness. In short, it is an earth-centric approach to literary studies that promotes the understanding of who we are, where we stand, how we should behave with our mother nature, etc. (Mishra, 2016).

Ecocriticism gets its inspiration from the three major American writers whose works celebrate nature as a life force, and the wilderness as manifested in America. They are Ralph Waldo Emerson (1803-1882), Margaret Fuller (1810-1850), and Henry David Thoreau (1817-1862). The trio belonged to the group of New England writers, poets, essayists, novelists, and philosophers collectively known as the transcendentalists, the first major literary movement in America to achieve 'cultural independence' from European models. R. W. Emerson had enjoyed the influence of nature in his first reflective prose narrative Nature. The writer here celebrates a nontraditional approach to nature which is popularly known as 'transcendentalism' (a theory that propounds that 'the divine' or 'god' pervades nature). He suggests that reality can be best perceived by studying nature. Fuller's Summer on the Lake During 1843 is a transcendental travelogue that encounters the American landscape at large. It is based in the Great Lakes region. Fuller here differentiates the utilitarian motives of the settlers and spiritual aesthetic aims of tourists (Mishra, 2016).

Anita Desai's Fire on the Mountains (1977) is a good example of an Ecocritical text dealing with the problem of animal killing, population explosion, moral degradation of man -all causing a 
threat to the ecology symbolized by frequent fire in the forest. Kamala Markandaya's Nectar in a Sieve (1954) represents nature as a destroyer and preserver of life. The novelist here has shown how the evils of industrialization spoil the sweet harmony of a peasant's life. Arundhati Roy's The God of Small Things (1997) is a portrayal of the exploitation of nature by human beings in the name of progress and modernization which is a dominant theme of the novel. The author here has shown her keen awareness of today's pressing environmental issues. The novelist has raised her voice for the environment, which is now under a great threat of pollution. In this novel, she not only exposes the massive degradation of nature but also reflects on the reason behind its dehumanization. Ruskin Bond's No Room for a Leopard (1998) presents the pathetic condition of the animals after deforestation. Bond's The Cherry Tree (2012), The Tree Lover (2017), Herriot's All Creatures Great and Small (2014), and many others are all about the chain which binds man and nature, as in the chain of the ecosystem, showing interdependence.

As a reflector of social circumstances, the selected picture books on environmental challenges provide a source of understanding regarding how trees play a crucial role in the ecosystem. Several studies have briefly discussed the environmental issues such as a story of a heron in Belgian comic strip (Heise, 2006), the imperial-environmental imagination in classic children's literature (Echterling, 2016), the ecological and social awareness in place-based stories (Gladwin, 2019), and the living wonder of trees (Wellborn, 2020). However, none of the studies explores the trees as the metaphor of Mother Earth that maintains a sustainable life for the ecosystem.

\section{METHODOLOGY}

There are five picture books used as the objects of this study. All data are in the form of verbal narration and pictures. The first picture book, A Tree is Nice by Janice May Udry (1984). The book consists of thirty-two pages, half in colors, and is destined for four to eight-year readers. This book won the Caldecott Medal in 1957 and has been reprinted by HarperCollins Publishers, New York. The second is The Giving Tree by Shel Silverstein (1992). This fifty-four page long story is considered an all-ages picture book. The pictures are in black and white. The book received the 1974 New York Times Outstanding Book Award. The third is Red Knit Cap Girl and The Reading Tree by Naoko Stoop (2014). The story is presented in forty pages. The fourth is Seasons Come, 
Seasons Go: Tree by Patricia Hegarty (2015). It is a peek-through twenty-six length pages picture book. The fifth is The Tree by Neil Layton (2016). This picture book is thirty-two pages directed for three-year-old and older readers. It was the shortlisted Gold Smarties Award. All books present trees as part of the conflict of the stories and children as the main characters.

Methodologically, this study employs a detailed analysis of the narrative and illustrative elements of picture books, respectively. Both elements will be selectively used to support the arguments of this essay. The discussion of the environmentalissues is informed by several relevant theories such as ecocriticism, trees as a metaphor, and literary elements. The study will be conducted by using a qualitative method that relies on the interpretation of text analysis (Hammarberg, Kirkman, \& de Lacey, 2016). Dawson (2002) opines that qualitative research explores attitudes, behavior, and experiences in narration. Kothari also clarifies that:

Qualitative research is especially important in the behavioral sciences where the aim is to discover the underlying motives of human behavior. Through such research we can analyze the various factors which motivate people to behave in a particular manner or which make people like or dislike a particular thing. $(2004$, p. 3$)$

Literary work, in this case, picture books, present narratives about interaction among characters which represent a real-life social issue. Since the objects of the study are picture books, the theories of the narrative elements both visual and verbal texts, are needed to discuss the issue represented by the story. The narrative is a plot or a story that consists of chronological events that tell how the story begins, what happens, and how the story ends. The main narrative elements are: "plot, characters, and setting" (Wellek \& Warren, 1995, p. 283). Picture books consist of two different elements, they are narrative and illustrative elements. The illustrations or the images and text are synchronized to form a balance that develops the story. The images in picture books are not only used to illustrate the narration but also to tell the story and define the mood and tone in the story (Russel, 1991).

There are several steps in conducting this study. First, reading the selected picture books and relevant theories. The stories are read several times to get a better understanding of the problem of the study. It is also necessary to read relevant theories to avoid misinterpretation. Second, selecting essential images and verbal passages represented the topic of ecocriticism to be analyzed. Third, 
examining the data; the narrative elements namely: characters and characterizations, setting, plot, and point of view along with the visual text, pictures, and colors, are evaluated by consulting ecocriticism theories.

This study scrutinizes five selected picture books: ATree is Nice by Janice May Udry (1984), The Giving Tree by Shel Silverstein (1992), Red Knit Cap Girl and The Reading Tree by Naoko Stoop (2014), Seasons Come, Seasons Go: Tree by Patricia Hegarty (2015) and The Tree by Neil Layton (2016). Hence, the discussion provides the plot summary and delineates how the images and the verbal narration present the idea of trees as the mother earth or the sources of life.

\section{RESULTS AND DISCUSSION}

\subsection{Trees in Visual Narratives: Enhancing Environmental Preservation through Picture} Books

Fang (1996) proposes several functions of illustrations in picture books: to present the narrative (characters, setting, plot, and point of view), to stimulate language acquisition (enrich vocabularies: constructing meanings through the connection between pictures and words), and to develop creativity (in terms of art appreciation). Those functions can be seen in both Seasons Come, Seasons Go: Tree by Patricia Hegarty and illustrations by Britta Teckentrup (2015) and A Tree is Nice by Janice May Udry and pictures by Marc Simont (1956).

In Seasons Come, Seasons Go: Tree, the visual text displays the colorful nature, the various colors of leaves and the animals around the trees. The owl as the character who witnesses the seasonal changing acts as to tell a story that trees are needed for every creature. The book begins with, "In the forest, all is still, / Gripped by winter's icy chill. / Owl sits watching in his tree... / No one sees as much as he" (Hegarty, 2015, pp. 3-4). Here, the exposition covers the setting and the main character.

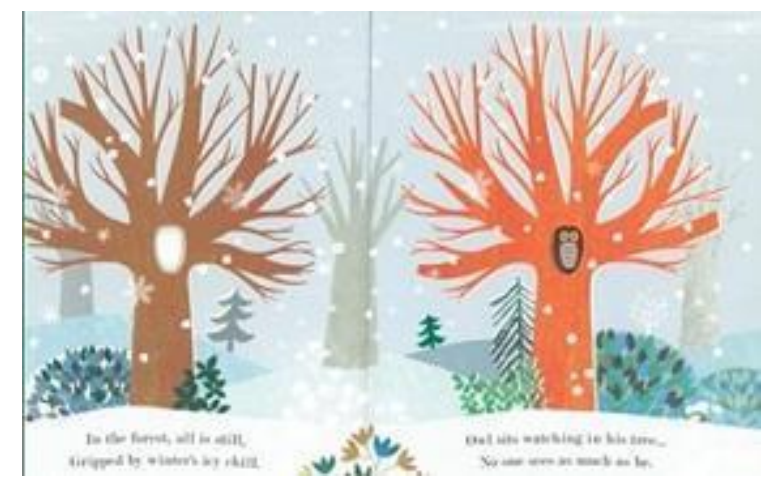


Figure 1. Owl in the tree

The visual text presents an owl inside the tree hole and the white dots spread the whole two pages with soft blue dominating the background to illustrate the verbal text. However, the pictures and colors here do not just accompany the text; they resonate the mood of the story. The owl, for instance, has two round big eyes, as how the owls commonly have, is seen observing its surroundings from the tree hole. Here, the kid readers learn that owls live in trees and in the winter, even when the trees do not have any leaves, an owl can take shelter from the cold by staying inside a tree hole. From the first two pages, all three functions of illustrations are performed: first, the pictures and colors accompany the narration to display the setting and the character; second the rhyme scheme a-a-b-b introduces not only the atmosphere of the story (still, chill, tree, he) but also the meaning of winter in the forest; and third, the colorful pages feasts one's eyes on the illustrations.

The book continues with the seasonal changing and the owl character keeps observing.

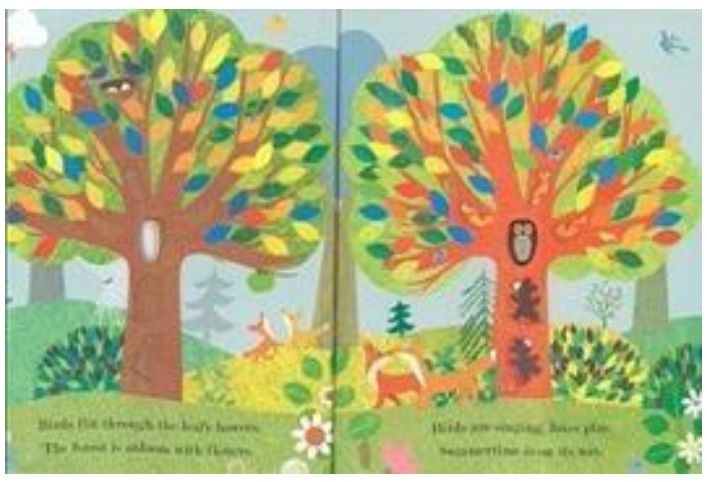

Figure 2. Crea tures around the tree

The narration, "Birds flit through the leafy bowers, / The forest is abloom with flowers. / Birds are singing, foxes play. / Summertime is on its way" (Hegarty, 2015, pp.9-10), is accompanied by a completely different situation of the tree and its surroundings. Now, the tree is full of leaves with various colors and although the owl is still staying inside the tree hole, there are other creatures just like what the text says, birds and foxes. The illustrations depict the concept of joyful summer, the creatures are now singing and playing as opposed to the winter. The tree here is displayed as a fun place for the animals. The importance of trees for the animals proposed by the narrator is then promoted into the values of trees for humans, "Juicy apples, ripe and sweet, / Almost ready for 
you to eat" (Hegarty, 2015, p. 12). The pronoun you here means the narrator interacts with the kid readers; the story does not only involve the owl character and its tree per se but also the readers. "[I]llustrations in picture books are meant to delight, to capture attention, to amplify or tell a story, to teach a concept, and to develop appreciation and awareness in children (Fang, 1996, p. 140). The phrase juicy apples to eat suggests the benefit of trees as sources of life. The pronoun you, then, is used to emphasize the province of the illustrations that it is important for you (kid readers) to preserve the forest (the trees).

In A Trees Is Nice, the characters who benefit from the trees are mainly humans. The book poses trees as providers for comfort, in terms of a shelter to hang around and protector form the weather conditions; and of course food. Here the kid readers are led to notice the importance of having trees around and are encouraged to plant one. The book begins with two simple sentences, "Trees are very nice. They fill up the sky" (Urdy, 1956, p. 2). The verbal text nice conveys the positive meaning from the very beginning; having trees around is something good.

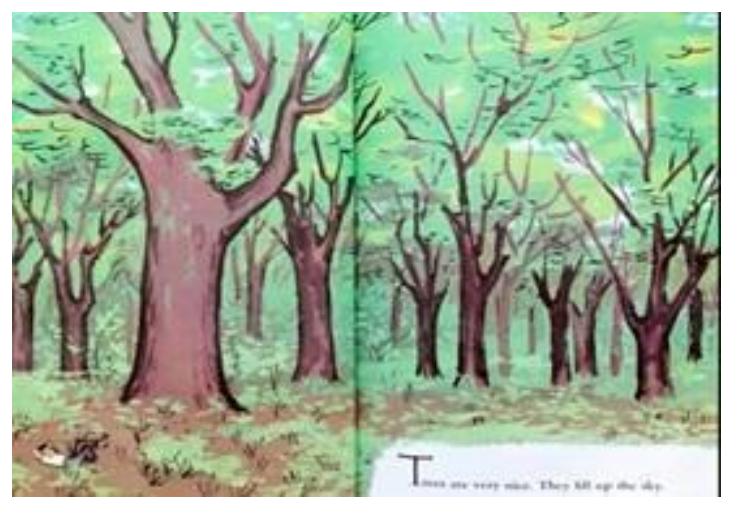

Figure 3. A kid enjoying the scenery of trees

The illustrations show a boy in the left corner lying under a tree. The dominant green color and trees that fill up the two pages implies that the boy is in a forest. The rest of the book then describes the advantages of having a tree, for each part of it has a function. "Even if you have just one tree, it is nice too. A tree is nice because it has leaves." (Urdy, 1956, p. 7). First, the text suggests that leaves, as part of a tree, can be used for something. "In the fall, the leaves come down and we play in them. We walk in the leaves and roll in the leaves. We build playhouses out of the leaves. Then we pile them up with our rakes and have a bonfire" (Urdy, 1956, p. 10). The leaves, when they leave the trees, can be plaything. Different from the previous book, the pronoun we is used instead 
of you. The pronoun we here offers the intimacy of both the narrator and the readers; we enjoy having the leaves.

Second, the narration describes the functions of the other parts of a tree. "A tree is nice because it has a trunk and limbs. We can climb the tree and see over all the yards. We can sit on a limb and think about things. Or play pirate ship up in the tree" (Urdy, 1956, p. 11).

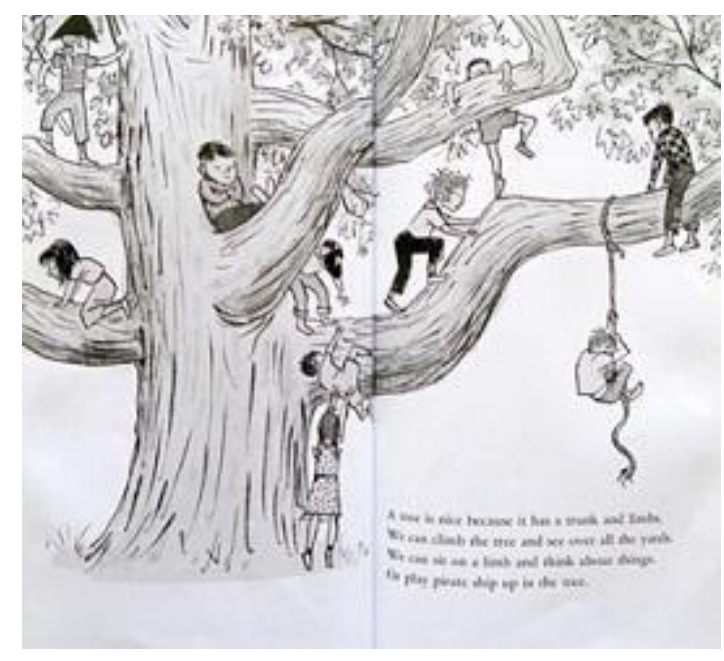

Figure 4. Kids on a tree

The illustrations of kids on a tree provides an experience to the readers; we can play and do lots of stuff on a tree. As the characters here are children, the kid readers are able to identify themselves with the characters, they can learn and mimic the acts. "If it is an apple tree we can climb it to pick the apples" (Urdy, 1956, p. 14), depicts the importance of trees as sources of life, as trees can provide humans something to eat.

Moreover, a tree is also beneficial for animals, just like what the first book insinuated. "Cats get away from dogs by going up the tree. Birds build nests in trees and live there"(Urdy, 1956, p. 15). "A tree is nice because it makes shade. The cows lie down in the shade when it is hot" (Urdy, 1956, p. 20). Through such narration, and helped by the illustrations, the kid readers gain knowledge that animals can take shelter in trees, just like humans. "A tree is nice for a house to be near. The tree shades the house and keeps it cool. The tree holds off the wind and keeps the wind from blowing the roof of the house sometimes" (Urdy, 1956, pp. 24-25). If the first part of the book has portrayed the profits of each part of a tree, here the book narrates the function of a tree as a whole. 
The message of the book as represented by the title, A Tree is Nice, voted at the end of the book, "A tree is nice to plant. You dig the biggest hole you can and put the little tree in. then you pour in lots of water and then the dirt. You hang the shovel back in the garage" (Urdy, 1956, p. 27).

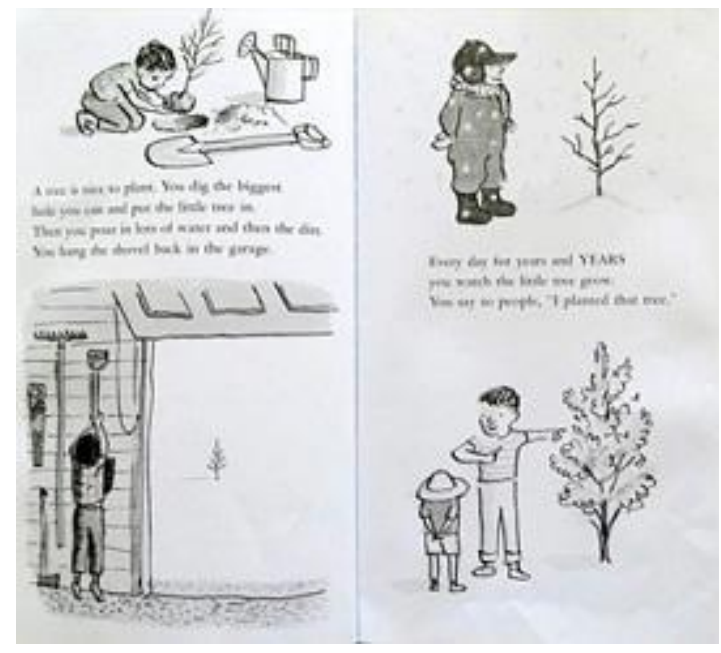

Figure 5. The process of planting a tree

The narration plays the instruction to plant a tree by using the pronoun you. The picture helps elude the idea of step by step planting a tree. As the book gradually points out the importance of having a tree, this ending makes it clear that in order to have such benefits from trees, each reader needs to plant one.

It can be concluded that the illustrations of picture books help readers to learn valuable lessons. "Picture books need to be taken seriously as a bimodal form of text in which the visual modality plays just as important a role as the verbal one in creating meaning and shaping readers" (Painter, Martin, Unsworth, 2012, p. 2). In this case, both the narration and the illustrations are used to enhance environmental preservation.

In Red Knit Cap Girl and the Reading Tree, the characters who benefit from the trees are not only a girl but also a bunny, a squirrel, a bear, a beaver, a fox, and other animals. The book sets out a tree as a library. The Red Knit Cap Girl, who loves reading books under the tree while listening to the leaves rustling and feeling the soft grass under her feet, initiates construction in building a library. She looks at the nook and says, "I have an idea" (Stoop, 2014). 


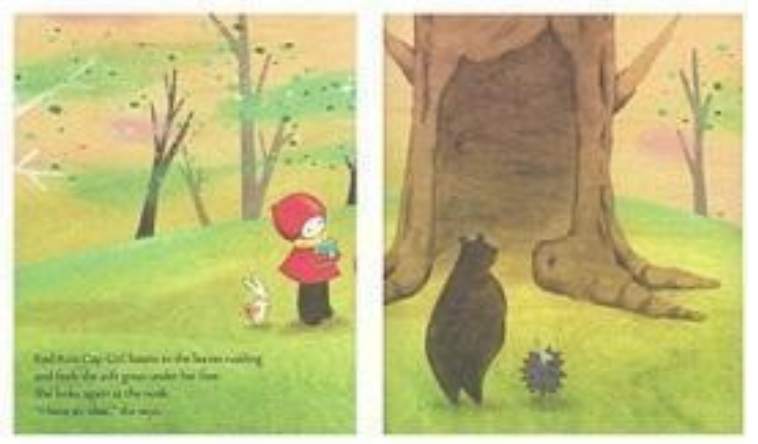

Figure 6. Pla nning to construct a library

The Red Knit Cap Girl and her friends turn a tree into a public library. Together they construct the library and supply books to it. Red Knit Cap Girl and her forest friends work together to turn one ordinary tree into something extraordinary, a library. After all, Red Knit Cap Girl and her friends gather in the library and they start reading. She is thankful for what her friends did. "Thank you for making our library. It is good to share books"(Stoop, 2014). This excerpt evidently shows that a tree plays a secondary significant role - a platform to provide harmony to its creatures and surroundings. Having a tree library serves to sustain its existence to its readers. The Red Knit Cap and her friends get the benefits from the tree as a part of the life cycle and as a tool to sustain the knowledge of its roles and advantages.
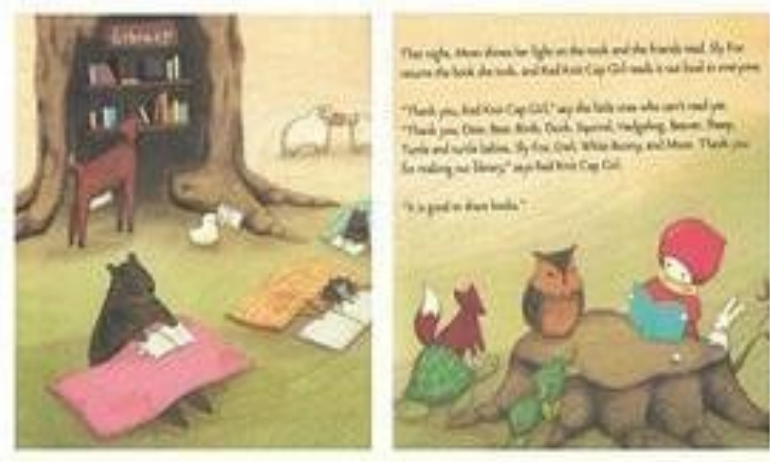

Figure 7. Ga thering and reading at library

Here all the characters are happy about what they have done and start reading. The Red Knit Cap Girl holds a sense of the existence of the tree and gets its advantage. She leads her forest friends to notice the importance of having trees around and enjoying them together.

The Tree delineates a couple who just bought a piece of land and plan to build a house. 


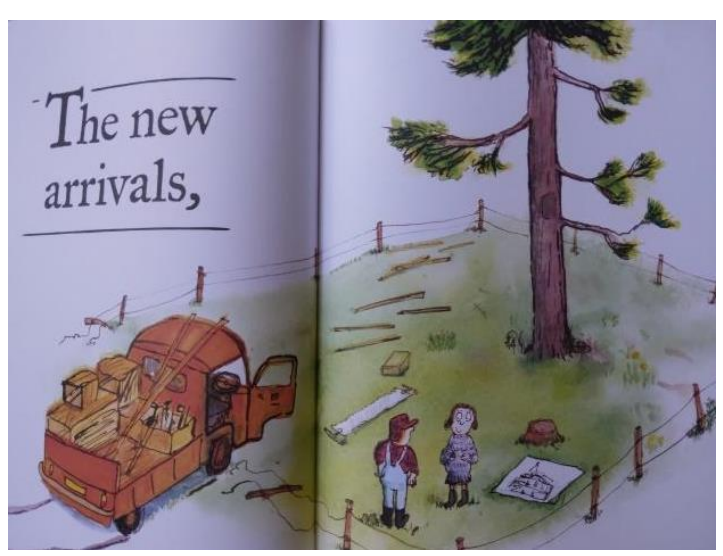

Figure 8. Altering their house design

Realizing that cutting one big tree on their land might cause damage to a nest on the tree, a hollow in the tree, and a burrow under the tree, they are wondering what would happen to them if it is cut down. Consequently, the couple agrees on readjust their house design by considering that for rabbits, birds and squirrels, the tree is home (Layton, 2016).

The couple has the means to participate in environmental sustainability that are only made possible with their right decision, which also defines their roles in their surroundings. They make a wonderful plan for all of them.

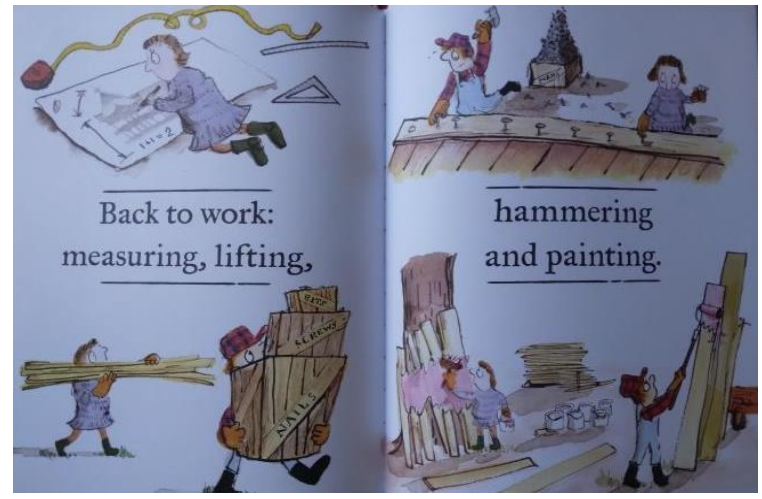

Figure 9. A couple constructing a house

The couple starts measuring, lifting, hammering, and painting a new house - a tree house. 


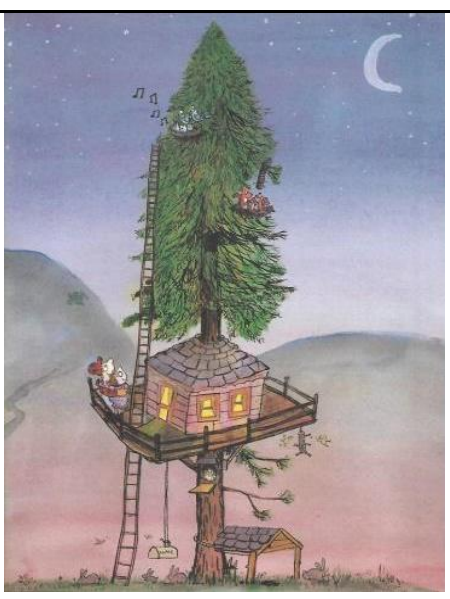

Figure 10. A tree house for all

Similar to the previous picture books' explanations, here both the narration and the illustrations are used to enhance environmental preservation. The tree is a home for many. This book highlights that there is a simple and a powerful way to live in harmony with the natural world.

\subsection{Trees as Mother Earth: Sustaining Life with Trees}

Trees do not simply exist to provide a shelter, a source of pulp, but a complex circle of life. They are social and cooperative creatures connected through multiplex ties of networks by which trees communicate their existence and essence with the environment they are living in. In this sense, trees are perceived as the powerful forces that connect and sustain the others that surround them as Mother Earth. This term is used to identify the Earth as a female. In line with this, Tong in Feminist Thought posits that "we thought of nature organically, as a benevolent female or nurturing mother, as someone who gave freely and generously of her bounty to us, her children" (2009, p. 240). In this sense, the tree is metaphorically perceived as the Mother Earth per se.

Trees as Mother Earth which do not ask for anything back from what they provide can be seen in both Seasons Come, Seasons Go: Tree and A Tree is Nice. They present the ideas that animals and humans are given things by the generous and bountiful trees. In Seasons Come, Seasons Go: Tree, the animals: bear cubs, squirrels, birds, foxes, and bees are taking shelter in the tree through winter, spring, summer, and autumn. Here, the tree is a loyal patron who is taking care of the inhabitants all year long, "The seasons have all come and gone.... And so begins another year" (Hegarty, 2015, pp. 25-26). 


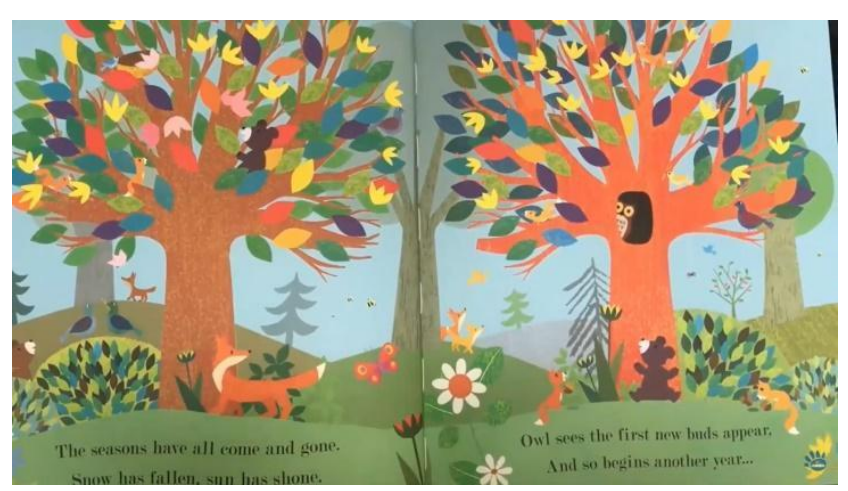

Figure 11. The tree and its inhabitants

This page shows how the creatures hold up their heads looking up to the tree as if they are waiting for the things the tree is giving them. The colorful leaves can be a representation of seasonal changes or different kinds of trees, which means various benefits given by the trees, especially in this case the trees in the forest.

Meanwhile, in A Tree is Nice, humans also depend on the gifts from the trees. As the setting changes from hills, woods, and housing areas, the trees are depicted to give more than just shelters. The shelters are given to animals, "Cats get away from dogs by going up the tree. Birds build nests in trees and live there," (Urdy, 1956, p. 15) "[t]he cows lie down in the shade when it is hot" (Urdy, 1956, p. 20) and humans, "[w]e can sit on a limb and think about things. Or play pirate ship up in the tree" (Urdy, 1956, p. 11), "[we] have picnics there too" (Urdy, 1956, p. 21). This protection is given not only for the sights, "[t]hey make everything beautiful" (Urdy, 1956, p. 6) but also ultimately when a tree can "holds off the wind and keeps the wind from blowing the roof the house" (Urdy, 1956, p. 25).

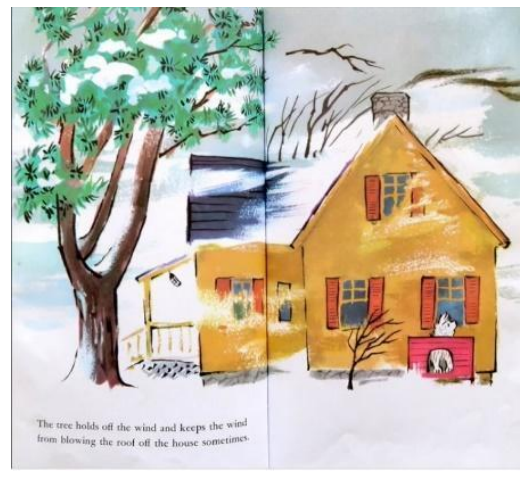

Figure 12. The tree as a protector

\section{(c) (1) (2)}


The picture here illustrates that even a building is given benefit from a tree. It provides a shield from harsh weather. Both Seasons Come, Seasons Go: Tree and A Tree is Nice present the idea that trees are metaphorically the Mother Earth who gives constantly to the creatures of the earth. This unconditional care is implied by the absence of what the creatures can give back to Mother Earth.

Explication of the characters taking advantages from the tree is not exclusively exposed in picture books. This satirical issue is depicted in The Giving Tree.

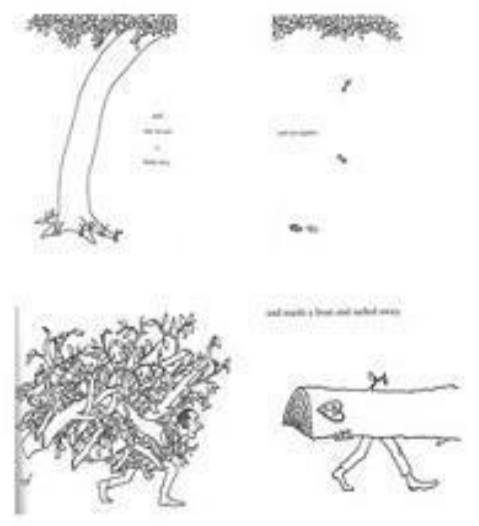

Figure 13. A boy benefitting from a tree

In this picture, both the narration and illustration disclose a child (boy) who gets all the benefits of a tree, namely a shelter, a place to play, fruit for food, to a tree trunk for building a house. From the beginning of the story when the boy is playing in the tree, "swing from the branches and eat apples", to his growing bigger and taking more from the tree, "And so the boy cut off her branches and carried them away to build his house" (Silverstein, 1992).

The process of utilizing the tree can be viewed as the boy's disconsolate decision towards his life. His attitude here is not a wager in that he is not aware of the consequences that may come along with his decision and he still somehow manages to do it. "And so the boy cut down her trunk and made a boat and sailed away" (Silverstein, 1992). The boy does such an excessive consumption of a tree as a capital means to live his life. Therefore, it behooves how the illustration and narration provide insight into how the tree is first utilized and is further exploited. On the contrary, the tree lets whatever the boy asks. Indeed, the tree offers everything she can give to 
meet the boy's needs. After a long time living his life far away from the tree, the boy comes back again. Eventually, all he needs is "just a quiet place to sit and rest" And the tree is still fulfilling his need, "Come, Boy, sit down. Sit down and rest" (Silverstein, 1992).

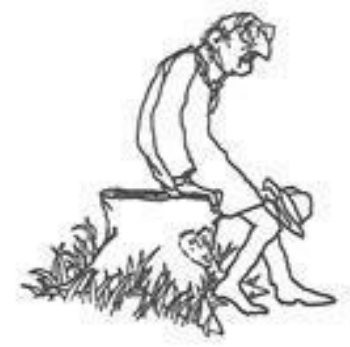

And the boy did.

Figure 14. A boy returning to his cut tree

This illustration highlights how a tree is used and expressly exploited by the boy as claimed by Tong, "if man is the lord of nature, if he has been given dominion over it, then he has control not only over nature but also over nature's human analog, woman. Whatever man may do to nature, he may also do to woman" $(2009$, p. 238). His negligence towards what happens to the tree declares his ignorance and greed. Not being ashamed of what he had done to the tree, he comes back and takes the benefit the tree has and still can offer. The steadfastness of the tree in providing whatever the boy needs implicates how the tree - as the Mother Earth - endows the boy. This picture book's discussion shows a different trend from the previous picture books that depict the benefits of trees as a metaphor for the source of survival for living together in an environment. Accordingly, taking care of trees means sustaining life for the creatures and living things around them.

\section{CONCLUSION}

Explication of the environmental issues in children's literature (Sigler, 1994; Dobrin, 2004; Massey, 2011; Echterling, 2016; Beeck, 2017; Goga, 2018) - particularly the role of trees (Hangrove, 1991; Margarith, 2014; Hulick, 2014; Mishra, 2016; Oldham, 2018; Stead, 2019) - is exclusively highlighted in picture books. Environmental issues both on the level of scholars and the literary works emerge from time to time. This discourse accentuates that it is still relevant and therefore needed to be discussed. The five picture books discussed in this article, though each was 
published in different times, emphasize trees as a crucial part of the environmental issues from diverse stories and epochs. Thus, they may provide comprehensive insights into how the stories are first perceived by the young readers and are further projected to reflect an awareness of sustainable living.

The five picture books' illustrations and narratives illuminate how trees live side by side with other living and nonliving things, evolving, adapting, and cooperating. Trees play a major role as Mother Earth that serves powerful forces that both connect and sustain the others that surround them. In this sense, picture books are a fruitful platform to enhance the understanding of the value of the ecosystem. Seasons Come, Seasons Go: Tree, A Tree is Nice, Red Knit Cap Girl and The Reading Tree, and The Tree clearly expose readers to see the importance of trees and how to live together with them. To live together with trees means to get the benefits from them and not to exploit them. Meanwhile, The Giving Tree depicts some effects of not taking care of the tree as a source of life, the Mother Earth. Children as readers can see what will happen when the trees are not treated as an important part of an ecosystem, the surroundings will be disadvantaged. To preserve trees means taking care of Mother Earth, therefore, to prolong its role in sustaining life.

This discussion provides an interesting inquiry into the extent to which picture books perform their parts in building environmental awareness. At times, trees as a part of an environment are rarely questioned from the perspective of ecocriticism. However, a deeper understanding of its values and functions for some circles of readers, particularly children, in the society could shed light on the importance of trees in sustaining life. The multimodal media, visual and verbal text, help children develop a sense of responsibility for preserving nature, in this case, trees, as they are the source of life.

\section{ABOUT THE AUTHORS}

Christy Tisnawijaya is currently teaching literature subjects at Universitas Pamulang. She is mesmerized by the beauty of picture books' various topics.

Geni Kurniati is personally and professionally interested in Women and Gender Studies and currently teaching the subjects to her students at Universitas Pamulang. Reading children's picture books is her favorite pastime.

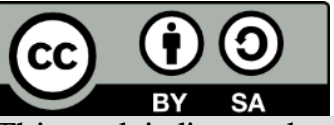




\section{REFERENCES}

Abram, D. (1996). The spell of the sensuous. Vintage Books.

Aslan, E. U., \& Bas, B. (2020). Ecocritical approach to children's literature: Example of “i am a hornbeam branch". Academic Journals, 15(12), 711-720. https://doi 10.5879/ERR2020.4063

Beeck, N. (2017). Environmental picture books: Cultivating conservationists. In: Nodelman (Ed.), More words about pictures (1 st ed.). Routledge.

Bond, R. (1998). No room for a leopard. Cambridge University Press.

Bond, R. (2012). The cherrytree. Penguin India.

Bond, R. (2017). The tree lover. Penguin Random House India.

Buell, L. (1995). The environmental imagination: Thoreau, nature writing and the formation of american culture. Harvard University Press.

Dawson, C. (2002). Practical research methods: A user-friendly guide to mastering research. Cromwell Press.

Desai, A. (1977). Fire on the mountains. Harpercollins.

Dobrin, S. (2004). Wild things: Children's culture and ecocriticism. https://www.researchgate.net/publication/37715895_Wild_Things_Children\%27s_Culture and_Ecocriticism

Echterling, C. (2016). Postcolonial ecocriticism, classic children's literature, and the imperialenvironmental imagination in "the chronicles of narnia". The Journal of the Midwest Modern Language Association, 49(1), 93-117.https://www.jstor.org/stable/44134678

Fang, Z. (1996). Illustrations, text, and the child reader: What are pictures in children's storybooks for?. Reading Horizons: A Journal of Literacy and Language Arts, 37(2). https://scholarworks.wmich.edu/reading_horizons/vol37/iss $2 / 3$

Frederick, S. (2012). Contemporary contemplation on ecoliterature. Authorpress.

Gladwin, D. (2019). Ecological and social awareness in place-based stories. The Canadian Journal of Irish Studies, 42, 138-157. https://www.jstor.org/stable/26693095

Goga, N. (2018). Children's literature as an exercise in ecological thinking. In: N. Goga \& L. Guanio-Uluru (Eds.), Ecocritical perspectives on children's texts and cultures: Critical approaches to children's literature. Palgrave Macmillan, Cham. https://doi.org/10.1007/978-3-319-90497-9_4

Hammarberg, K., Kirkman, M., \& de Lacey, S. (2016, March 1). Human reproduction. Oxford Academic. https://academic.oup.com/humrep/article/31/3/498/2384737

Hangrove, N. (1991). Faulkner's the wishing tree as children's literature. Association Quarterly, 132-140. https://doi 10.1353/chq.1991.0027

Hegarty, P. (2015). Seasons come, seasons go: Tree (B. Teckentrup, Illus.). Little Tiger Kids.

Heise, U. K. (2006). The hitchhiker's guide to ecocriticism. PMLA, 121(2), 503-516. https://www.jstor.org/stable/25486328

Herriot, J. (2014). All creatures great and small. Griffin.

Howarth, W. (1996). Some principles of ecocriticism. University Press of Virginia.

Hulick, J. (2014). Review of the book red knit cap girl to the rescue by naoko stoop. Bulletin of the Center for Children 's Books, 67(5), 285. doi: 10.1353/bcc.2014.0074. 
Kothari, C. R. (2004). Research methodology: Methods \& techniques. (2nd ed). New Age International Publishers.

Layton, N. (2016). The tree (N. Layton, Illus.). Candlewick Press.

Margarith, R. (2014). "The giving tree" at fifty: Sadder than i remembered. "The Giving Tree" at Fifty: Sadder Than I Remembered | The New Yorker

Markandaya, K. (1954). Nectar in a sieve. Penguin India.

Massey, G., \& Bradford, C. (2011). Children as ecocitizens: Ecocriticism and environmental texts. In: K. Mallan \& C. Bradford (Eds)., Contemporary children 's literature and film: Engaging with theory (109-126). Palgrave Macmillan.

Mishra, S. K. (2016). Ecocriticism in children's literature: An analysis of amit garg's two tales. Galaxy, 5(5), 91-97.

Oldham, J. (2018). Tree: A peek-through picture book by patricia hegarty illustrated by britta teckentrup. Library Intern Book Reviews. 186. https://digitalcommons.cedarville.edu/intern_book_reviews/186

Painter, C., Martin, J. R., \& Unsworth, L. (2012). Reading visual narratives: Image analysis in children's picture books. Equinox Publishing Ltd.

Roy, A. (1997). The god of small things. Penguin India.

Russel, D. L. (1991). Literature for children: A short introduction. Longman.

Sigler, C. (1994). Wonderland to wasteland: Toward historicizing environmental activism in children's literature. Children's Literature Association Quarterly, 19(4), 148-153. https://doi: 10.1353/chq.0.1011.

Silverstein, S. (1992). The giving tree (S. Silverstein, Illus.). HarperCollins Publishers.

Stead, P. (2019). Be gentle: What is the reason for kindness?. Virginia Quarterly Review, 95(3), 166-177. https://www.muse.jhu.edu/article/734012.

Stoop, N. (2014). Red knit cap girl and the reading tree (N. Stoop, Illus.). Little Brown Books.

Tong, R. (2009). Feminist thought. Westview Press.

Urdy, J. N. (1984). A tree is nice (M. Simont, Illus.). HarperCollins Publishers.

Wellborn, T. (2020). Pando: The secret life of trees. Dialogue: A Journal of Mormon Thought, 53(2), 143-159. https://www.jstor.org/stable/10.5406/dialjmormthou.53.2.0143

Wellek, R., \& Warren, A. (1995). Theory of literature [Teori kesusastraan]. PT Gramedia Pustaka Utama. 